\title{
USANDO O TRANSLOG PARA REGISTRAR OS ACIONAMENTOS DE TECLAS E MOUSE E RASTREAR OS MOVIMENTOS OCULARES DE TRADUTORES ${ }^{1}$
}

\section{TRACKING TRANSLATORS' KEYSTROKES AND EYE MOVEMENTS WITH TRANSLOG}

\author{
Arnt Lykke JAKOBSEN ${ }^{2}$ \\ Tradução de: Myrna Michelle Evangelista MAIA ${ }^{3}$
}

\begin{abstract}
Resumo: Embora o registro de acionamentos de teclas e mouse (do inglês, key logging) abra muitas possibilidades para o estudo do processo tradutório, a inclusão do rastreamento ocular (do inglês, eye tracking) aumenta consideravelmente nossa capacidade de conhecer os tipos de processos que o tradutor executa em determinado momento. Apresenta-se, neste trabalho, uma descrição de como o software Translog foi remodelado tecnologicamente no contexto do projeto Eye-to-IT, financiado pela União Europeia, para poder integrar o registro de acionamentos de teclas e mouse com o rastreamento ocular e como os dados brutos da combinação desses dois métodos foram representados. Em seguida, disponibiliza-se uma análise de uma pequena amostra de dados a fim de se proceder a uma formulação provisória de um recorrente microciclo de processamento em seis etapas, o qual introduz a palavra "âncora" como um novo conceito. Sugere-se, de forma otimista, que um ciclo básico do tipo apresentado pode funcionar tanto como base para uma análise computacional de grandes volumes de dados de movimentos oculares e de acionamentos de teclas e mouse, quanto como o centro de um modelo computacional da tradução humana.
\end{abstract}

Palavras-chave: Processos tradutórios. Registro de acionamentos de teclas e mouse. Rastreamento ocular. Translog.

\section{Introdução}

O software Translog foi originalmente desenvolvido para registrar somente os acionamentos de teclas executados pelos tradutores. Uma sequência completa e cronometrada desses acionamentos fornece uma visão detalhada de todo o processo de digitação por meio do qual uma tradução se materializa. O registro de dados desse tipo possibilita estudar

\footnotetext{
${ }^{1}$ Agradecemos ao autor e à editora John Benjamins Publishing Company a gentileza de cederem os direitos para a publicação desta versão traduzida. Referência do artigo original: JAKOBSEN, Arnt Lykke. Tracking translators' keystrokes and eye movements with Translog. In: ALVSTAD, Cecilia; HILD, Adelina; TISELIUS, Elisabet (Ed.). Methods and strategies of process research: integrative approaches in translation studies. Amsterdã: John Benjamins, 2011a. p. 37-55. O volume onde o texto original foi publicado se encontra à venda no site da editora John Benjamins: https://benjamins.com/\#catalog/books/btl.94/main Acesso em 13 de dezembro de 2017.

O autor é grato a dois pareceristas anônimos e aos editores do volume pelos seus comentários bastante construtivos.

${ }^{2}$ Copenhagen Business School

${ }^{3}$ Tradutora freelance. Graduanda em Tradução pela Universidade Federal da Paraíba. Atuou como pesquisadora na área de Competência Tradutória na UFPB. E-mail: myrnamichelle@gmail.com. Tradução supervisionada pela Prof $^{\mathrm{a}} \mathrm{Dr}^{\mathrm{a}}$ Tânia Liparini Campos.
} 
fenômenos cognitivos como a segmentação, com base na distribuição de pausas, e fenômenos relacionados à escrita, como edições e correções. No entanto, embora algumas vezes seja possível relacionar dados de produção textual com fenômenos de compreensão, na maioria das vezes é possível apenas especular os processos de compreensão envidados por um tradutor antes de digitar uma solução, uma vez que o único dado registrado é uma pausa.

A inclusão do rastreamento ocular no registro dos acionamentos de teclas e mouse acrescenta informações muito importantes acerca do que ocorre nos momentos em que não há atividades de digitação. Pode-se rastrear a leitura do texto-fonte, assim como a leitura e o monitoramento do texto-alvo, além da alternância de foco do texto-fonte para o texto-alvo e vice-versa. Tais informações aumentam radicalmente nossas chances de reconstruir os processos de compreensão que precedem a produção textual e a forma como os processos de compreensão e produção se coadunam.

A captura dos movimentos oculares tornou-nos conscientes da magnitude do trabalho executado pelos olhos - e pelo cérebro humano - durante a leitura. Há vários estudos importantes sobre leitura (RAYNER; POLLATSEK, 1989; RAYNER, 1998; RADACH; KENNEDY; RAYNER, 2004); porém, ainda não se investigou o tipo de leitura que faz parte do processo de tradução escrita. Em um experimento em que se registraram os movimentos oculares em tarefas de leitura de um texto em língua estrangeira para sua compreensão e se compararam esses movimentos com aqueles encontrados em tarefas de tradução envolvendo digitação do texto-alvo, observamos que a tradução escrita envolve muito mais trabalho dos olhos e parece ser uma tarefa consideravelmente mais dispendiosa, em termos cognitivos, do que apenas a leitura e compreensão de um texto ou até mesmo a leitura e tradução oral desse texto (JAKOBSEN; JENSEN, 2008, traduzidos neste volume).

A observação dos movimentos oculares ajuda a entender melhor a complexidade mecânica da tarefa de tradução escrita, mas os dados do olhar (gaze) no texto também nos ajudam a chegar mais perto do cerne dos desafios cognitivos da tradução. O pressuposto fundamental aqui é que há uma correlação entre os dados comportamentais "externos" e o processamento cognitivo "interno". Embora se tenha demonstrado que a chamada hipótese olho-mente (JUST; CARPENTER, 1980) - segundo a qual os olhos fixam naquilo de que a mente se ocupa em dado instante - não se aplica em todos os momentos do processo de leitura (cf. HYÖNÄ; RINCK, 2003), os dados dos movimentos oculares ainda assim fornecem uma excelente janela para a mente. Ao visualizarmos a forma como se dá a leitura e como esta 
interage com a digitação, obtemos a melhor imagem disponível de como os processos tradutórios são coordenados na mente.

\section{Análise dos dados de acionamentos de teclas e mouse (key logging)}

A motivação original para o desenvolvimento do software Translog foi a intenção de complementar com evidências "mais robustas", registradas pelo computador, os dados processuais de verbalização do pensamento em voz alta (do inglês, think aloud, ou TAP) obtidos em experimentos de tradução humana. O pressuposto metodológico por trás dessa intenção foi a convicção de que, se fosse observada convergência entre os dados de verbalização, qualitativos, e os dados comportamentais, quantitativos, nossas hipóteses sobre os processos tradutórios ganhariam um importante suporte.

A primeira versão do Translog, desenvolvida em 1995, tinha três funções principais. Exibia automaticamente o texto-fonte como uma unidade completa, em parágrafos, em frases ou em segmentos definidos pelo pesquisador. A função principal de registro, no componente então chamado Writelog (JAKOBSEN; SCHOU, 1999), capturava todos os acionamentos de teclas, incluindo os toques de exclusão e navegação do cursor - mas ainda sem os cliques no mouse - que eram realizados durante a execução de uma tarefa de tradução e, em seguida, salvava esses dados em um arquivo de extensão .log. Posteriormente, as informações armazenadas nesse arquivo podiam ser exibidas de dois modos: como uma reprodução dinâmica ou como uma sequência linear de acionamentos de teclas.

A reprodução podia ser executada em diferentes velocidades, o que permitia ao pesquisador examinar visualmente - em velocidade normal, ou em velocidade mais lenta ou mais acelerada - a dinâmica temporal da produção do texto traduzido. A reprodução em alta velocidade fornecia evidência visual direta da estrutura segmentada da produção do texto traduzido. Já a reprodução em baixa velocidade tinha o efeito semelhante ao de uma lente de aumento. Em nosso grupo de pesquisa, logo descobrimos que, ao empregarmos a função de reprodução (replay) para auxiliar a memória dos participantes durante a retrospecção, nós conseguíamos obter dados com bastante riqueza. Quando os participantes tinham a oportunidade de observar a reprodução de seus acionamentos de teclas enquanto estavam sendo entrevistados, eles pareciam lembrar imediatamente, e com muita precisão, o que tinha se passado em suas mentes em dado momento durante a tarefa de tradução ${ }^{4}$. Embora não se

\footnotetext{
${ }^{4}$ Há uma descrição detalhada do método em Englund Dimitrova (2005, p. 66) e uma ampla discussão sobre a retrospecção como método de pesquisa em Englund Dimitrova e Tiselius (2009).
} 
pudesse saber com certeza se o que estava sendo relatado na retrospeção era tão confiável quanto o conteúdo de uma verbalização concomitante, os dados revelados dessa maneira tinham toda a aparência de serem evidências verdadeiras. Geralmente eram dados muito detalhados e expressos com espontaneidade e grande conviç̧ão pelos participantes.

Uma grande vantagem da obtenção de dados retrospectivos, além de sua riqueza e exatidão - ao menos pelo que parecia ser o caso -, foi que não havia suspeita de que esse método exercesse impacto sobre os dados primários (i.e., os acionamentos de teclas), uma vez que eram coletados após o evento. O pressuposto de que a verbalização não tinha efeito sobre o processamento primário se o conteúdo verbalizado estivesse disponível, em formato verbal, na memória de curto prazo (ERICSSON; SIMON, 1984) não foi corroborado por nossos resultados em experimentos em Copenhague, os quais indicaram que a verbalização concomitante teve um efeito degenerativo sobre o processamento cognitivo (cf. JAKOBSEN, 2003, traduzido neste volume). Por tais motivos, vários outros experimentos foram realizados com verbalização retrospectiva auxiliada por reprodução do processo tradutório, em vez de fazerem uso da verbalização concomitante (e.g., HANSEN, 2005; 2006).

No final de 1999, Lasse Schou terminou de programar a primeira versão do Translog para Windows (98), a qual foi chamada de Translog 2000. Versões experimentais desse novo software ficaram disponíveis para teste e uso no projeto TRAP (1996-2000), desenvolvido na Copenhagen Business School (CBS). As três funções básicas ainda eram as mesmas: um projeto criado no módulo Translog Supervisor (anteriormente denominado Translog) era exibido no Translog User (anteriormente denominado Writelog), o qual registrava os dados de acionamentos de teclas e mouse com seus respectivos tempos e salvava os dados binários em um arquivo com extensão .log que tinha de ser aberto (para reprodução e exibição de uma representação linear) no módulo Translog Supervisor. O programa incluía um pequeno componente estatístico, que calculava, por exemplo, o tempo da tarefa e o número total de acionamentos de teclas.

Duas das principais aplicações dessa versão do Translog foram o estudo das fases do processo tradutório e de como estudantes de tradução e tradutores profissionais ou expertos segmentam a digitação do texto em processo de tradução. No âmbito do projeto Expertise, vários experimentos demonstraram que os tradutores profissionais ou expertos dedicavam mais tempo e esforço à conferência e à revisão de suas traduções do que os estudantes de tradução, embora o produto tradutório dos primeiros já tivesse uma qualidade superior na fase de redação (drafting). Também se mostrou claramente que os tradutores expertos 
segmentavam seus textos em unidades maiores do que aquelas encontradas entre os estudantes. Esse é um forte indício de que os tradutores expertos lidam com suas tarefas tradutórias de uma maneira distinta do ponto de vista cognitivo, processando sequências de texto e unidades de tradução maiores do que aquelas processadas pelos estudantes. A comparação do tamanho dos segmentos nos trechos iniciais da fase de redação com o tamanho dos segmentos nos trechos finais da fase de redação forneceu suporte empírico quantitativo para a hipótese dos efeitos facilitadores ${ }^{5}$.

$\mathrm{O}$ fato de o Translog fornecer um registro completo de todas as ações de revisão o tornou adequado para o estudo de práticas editoriais, como a distribuição da revisão on-line (em tempo real, imediata), executada durante a fase de redação, e a revisão final, além de contribuir para estudos mais qualitativos da própria revisão. O software também foi aplicado ao estudo de diversos fenômenos de distração na produção de traduções escritas (HANSEN, 2005).

Embora o registro de acionamentos de teclas e mouse forneça dados para a compreensão do tamanho e da composição dos segmentos a partir dos quais os tradutores constroem o texto-alvo, é muito difícil saber, com base nesse registro, qual atividade cognitiva estava sendo executada durante as pausas entre os segmentos, por que essas pausas tiveram determinada duração ou por que razão elas ocorreram. Na maioria dos registros que fizemos, os segmentos eram relativamente curtos, com menos de quatro ou cinco palavras e com pausas de aproximadamente $2 \mathrm{~s}$ ou mais entre eles. Essa observação parecia sugerir um processo que alternava entre a leitura e compreensão do texto-fonte, a formulação mental da tradução e a digitação física da tradução. Contudo, em alguns casos, os segmentos registrados eram tão longos que excediam, em muito, a capacidade de armazenamento da memória de curto prazo - os chamados casos de desempenho de pico (do inglês, peak performance), conforme proposto por Jakobsen (2005) - e não podiam ser explicados em termos de uma sequência contínua de compreensão, formulação e digitação da tradução. As ocorrências desse tipo pareciam indicar que pelo menos alguns tradutores eram capazes de alimentar continuamente suas memórias de curto prazo e processar as informações ao mesmo tempo em

\footnotetext{
${ }^{5} \mathrm{O}$ termo "efeitos facilitadores" tem sido utilizado nos estudos da aquisição de L2 e do bilinguismo desde a década de 1960 para indicar características da L1 que facilitam a aquisição da L2. Nas pesquisas em tradução, o termo refere-se à observação de que a tradução de um texto fica mais fácil e mais rápida à medida que o tradutor vai se familiarizando com esse texto. Englund Dimitrova (2005, p. 98) afirma: "Investigar-se-á também o possível efeito facilitador existente durante a fase de redação da tarefa tradutória - mais especificamente, se existem diferenças na segmentação e/ou no número de caracteres por segmento no início e no final da fase de redação".
} 
que digitavam a tradução. Tal evidência de sobreposição das atividades de compreensão, formulação e digitação foi um forte indício da ocorrência de processamento paralelo.

Mas essa era apenas um dos problemas que precisavam de evidências complementares. Basicamente, só podíamos especular, a partir do ambiente linguístico em que as pausas ocorriam, o porquê de sua ocorrência e os processamentos com os quais elas poderiam estar correlacionadas. Os dados, oriundos da extremidade final do processo de tradução, estavam abertos a múltiplas interpretações. Não era possível saber sequer se as pausas eram sempre causadas por fenômenos relacionados à tarefa de tradução propriamente dita ou por fatores totalmente irrelevantes à execução de tal tarefa. Um caminho óbvio para buscar evidências complementares era tentar descobrir qual era o foco do olhar dos tradutores durante a tarefa de tradução.

\section{Possíveis benefícios advindos da inclusão de dados do olhar (eye tracking) aos dados de acionamentos de teclas e mouse (key logging)}

Uma das ambições fundamentais no projeto Eye-to-IT (2006-2009), financiado pela União Europeia, era desenvolver um aplicativo que integrasse os dados de leitura (dados do "olhar" ou dos "movimentos oculares") obtidos a partir de um rastreador ocular com os dados de escrita já disponíveis em programas como o Scriptlog, o Inputlog e o Translog${ }^{6}$. O desafio era associar as informações obtidas pelo rastreador ocular às palavras que, de fato, são lidas pelo tradutor.

Uma hipótese básica era que os dados dos movimentos oculares forneceriam evidências da leitura do texto-fonte, de modo que os processos de compreensão desse texto pudessem ser estudados separadamente dos processos de produção textual e comparados com outros processos de leitura não relacionados ao processo de tradução. Esperava-se obter dados de movimentos oculares sem interrupções ou com poucas interrupções durante toda a tarefa de tradução e poder "preencher" com dados interessantes a maioria das pausas ocorridas durante a digitação.

Outra hipótese era que a integração entre dados de movimentos oculares e dados de acionamentos de teclas e mouse forneceria novas oportunidades para se pesquisar a dinâmica de como a atividade de compreensão do texto-fonte, refletida nos movimentos oculares do tradutor, se coaduna com a atividade de produção do texto-alvo, refletida principalmente nos

6 Cf. SCRIPTLOG. Disponível em: <http://scriptlog.net/>; INPUTLOG. Disponível em: $<$ http://www.inputlog.net>; TRANSLOG. Disponível em: <http://translog.dk>. Acesso em: 2 dez. 2017. 
acionamentos de teclas e mouse, mas possivelmente também no olhar na tela. Além disso, havia a hipótese de que, assim como a distribuição das durações das pausas no processo de escrita parece estar relacionada com a dificuldade ou facilidade da tradução, os padrões de duração das fixações e dos movimentos oculares, como as regressões, são correlacionáveis com a dificuldade ou facilidade de compreensão do texto-fonte, de produção textual e/ou de tradução. Por fim, tomou-se a hipótese de que, se fosse possível associar, de modo confiável, os dados do rastreador ocular às palavras lidas na tela em tempo real - isto é, se os dados do rastreador ocular (que fornecem a posição do olhar) pudessem ser "traduzidos" instantaneamente em informações sobre as palavras que o tradutor estava olhando -, poderíamos explorar esse mapeamento em tempo real para dar suporte à tradução por meio de janelas que seriam ativadas pelo olhar do tradutor.

\section{Desenvolvimento do Translog no âmbito do projeto Eye-to-IT}

Logo ficou claro que seria difícil adaptar o Translog 2000 para cumprir as promessas feitas na descrição da pesquisa do projeto Eye-to-IT. Decidiu-se, então, que Lasse Schou reescreveria completamente o programa em linguagem C\#, usando o ambiente .NET 2.0, da Microsoft, e introduzindo o Unicode 8 (para acomodar caracteres não latinos) e a linguagem de marcação XML para a geração dos arquivos. O resultado foi o Translog 2006, atualmente distribuído na versão "acadêmica". A versão distribuída não inclui o componente de registro do olhar que foi desenvolvido experimentalmente para o projeto Eye-to-IT. ${ }^{7}$

Os grandes desafios técnicos do projeto Eye-to-IT foram encontrar uma maneira de integrar os dados de acionamentos de teclas e mouse com os dados do olhar na tela de tal modo que fosse possível obter uma sequência perfeitamente cronometrada desses dados e encontrar uma forma de associar, em tempo real, as informações do rastreador ocular às palavras que estavam sendo lidas pelo usuário. Esse desafio técnico e de programação foi enfrentado em conjunto por Lasse Schou e Oleg Spakov; e, no decorrer do projeto Eye-to-IT (2006-2009), um módulo de associação entre olhar e palavra (do inglês, gaze-to-word mapping, ou GWM), desenvolvido na Universidade de Tampere ${ }^{8}$, foi integrado com sucesso a uma versão experimental do Translog.

\footnotetext{
${ }^{7}$ Está em fase de teste uma versão que inclui o registro de acionamentos de teclas e mouse, os movimentos oculares, a gravação de áudio e a associação, em tempo real, entre olhar e palavra.

${ }^{8}$ A solução foi inspirada pelo projeto iDict, desenvolvido na Universidade de Tampere (HYRSKYKARI et al., 2000; HYRSKYKARI 2006).
} 
Amostras do olhar na tela obtidas por meio do rastreador ocular Tobii 1750 foram interpretadas como sacadas ou fixações, e o módulo GWM associou automaticamente as fixações a uma palavra do texto-fonte ou do texto-alvo com base nas posições das palavras na tela e em alguns ajustes implementados por um algoritmo que representava um modelo rudimentar de leitura. Os dados brutos do olhar eram salvos em arquivos separados; e apenas os dados processados pelo GWM e interpretados (com a sequência de fixações de duração específica relacionadas às palavras) eram registrados no Translog. $\mathrm{O}$ resultado da aplicação Translog/GWM era um registro perfeitamente cronometrado da sequência das fixações em palavras na tela e dos acionamentos de teclas e mouse (cf. Figuras 2 e 3). No Translog, os dados podiam ser representados linearmente com informações, em milissegundos, referentes aos intervalos entre os eventos de fixações do olhar e de acionamentos de teclas e mouse. Além disso, os dados podiam ser reproduzidos com os acionamentos de teclas aparecendo dinamicamente, como em versões anteriores do Translog, mas agora também destacando, de maneira dinâmica, as fixações do usuário nas palavras do texto-fonte ou do texto-alvo durante o período de duração dessas fixações (cf. Figura 1).

Figura 1 - Exibição do texto-fonte no Translog 2006 (janela superior esquerda) e um trecho da representação linear dos dados do olhar na tela e dos acionamentos de teclas e mouse (janela do lado direito) mostrando a posição atual do cursor após [Source gaze: deforestation].

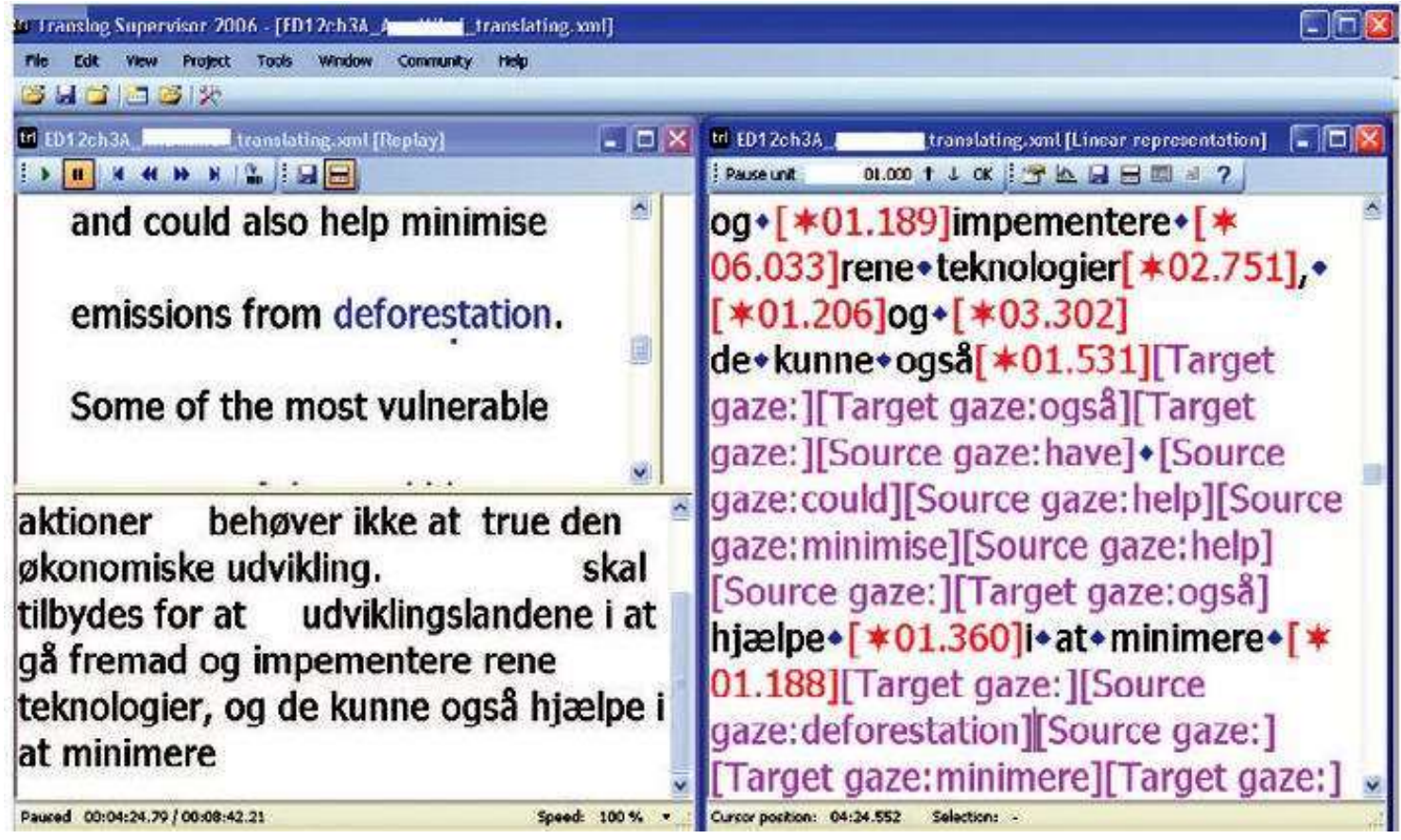

Nota: Quando ativada, a função replay mostra a sequência de acionamentos de teclas e mouse na janela inferior esquerda enquanto destaca a palavra do texto-fonte ["deforestation"] que está sendo lida, na velocidade de exibição previamente selecionada. Algumas vezes, não foi possível mapear as fixações no texto-fonte e (com maior frequência) no texto-alvo [Target gaze:]. A ocorrência de pausas com duração superior a $1 \mathrm{~s}$ em que não 
houve registro de dados (e.g., [*02.751]) indica que o tradutor não estava olhando para a tela, mas provavelmente para o teclado.

Em versões anteriores do Translog, os dados brutos eram registrados em código binário, ao passo que, no Translog 2006, todos os dados brutos passaram a ser armazenados em código XML, de acesso aberto. As Figuras 2 e 3 mostram um fragmento dos dados subjacentes à representação da Figura 1. A Figura 2 apresenta informações sobre o tipo de "evento" [fixação (7), acionamento de tecla (1), sinal de sincronização (6)] registrado. O parâmetro Value indica o subtipo de evento ocorrido [fixação no texto-fonte (1), fixação no texto-alvo (2); toque na barra de espaço (32), toque na letra $H$ (104) etc.]. Os parâmetros Cursor e Block indicam, respectivamente, o momento em que dado evento ocorreu em uma sequência de eventos e o número de posições que o cursor avançou durante o evento. $\mathrm{O}$ parâmetro Time indica o tempo (em h:min:s:ms) em que determinado evento ocorreu, partindo do momento em que a tarefa teve início.

Figura 2. Trecho do registro em XML de alguns dados brutos subjacentes à representação mostrada na Figura 1

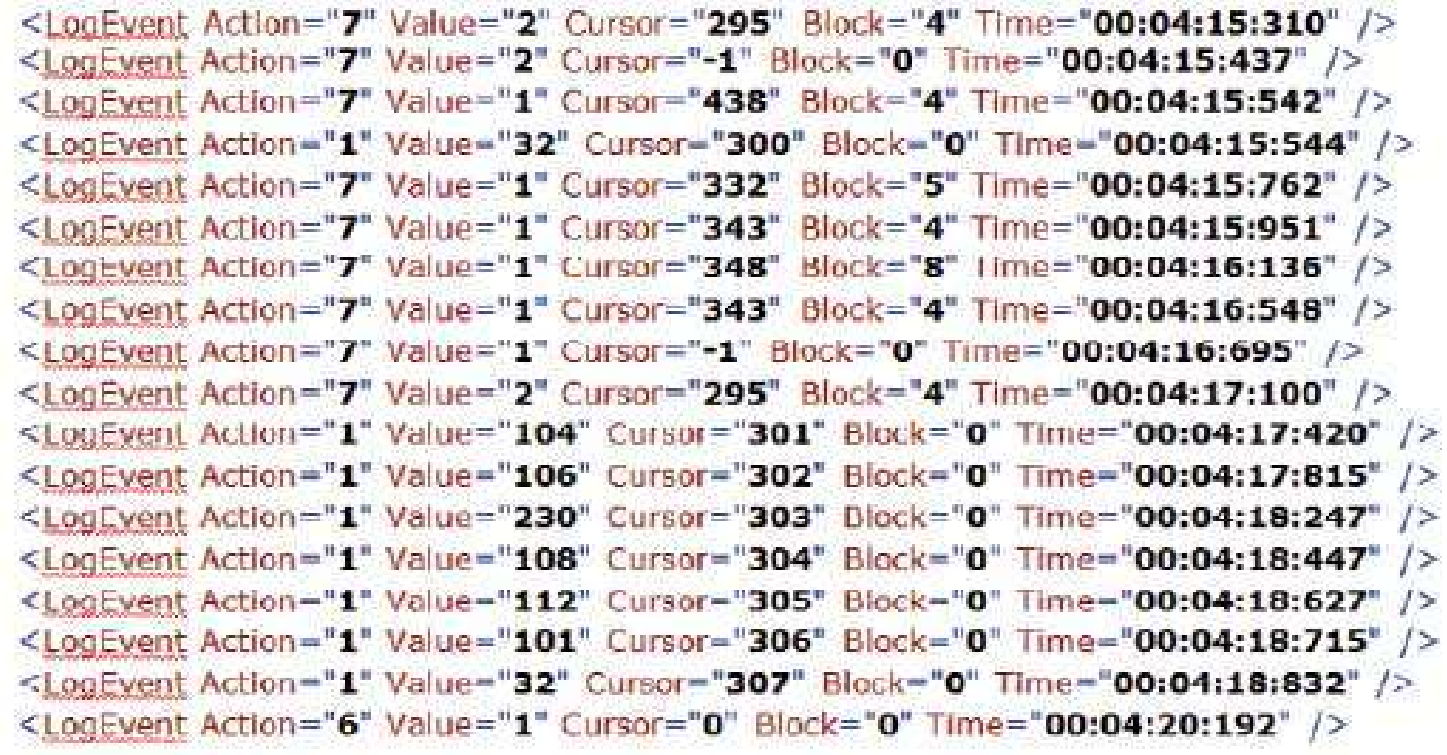

$\mathrm{Na}$ primeira linha da Figura 2, <LogEventAction="7" Value="2"...Block="4"...> indica que o LogEvent foi um evento de olhar (“7”) na janela do texto-alvo (“2”), onde a palavra olhada ["også"] tinha quatro caracteres (Block="4"). Na terceira linha, $<\operatorname{LogEventAction="7"Value="1"...>~representa~a~fixação~em~uma~palavra~com~quatro~letras~}$ ["have"] no texto-fonte. Na quarta linha, $<$ LogEventAction="1"Value="32"... $>$ indica que a 
tecla de número ASCII/Unicode 32, [<espaço>], foi pressionada e que o espaço foi inserido na posição 300 no tempo indicado. Em seguida, ocorrem cinco fixações em palavras do textofonte [“could", "help", “minimise", "help", Ø] e uma no texto-alvo [“også”], após as quais houve uma sequência de acionamentos de teclas e mouse para a produção de "hjcelpe" no texto-alvo. O LogEvent 6 indica um sinal de sincronização enviado pelo Translog.

Figura 3. Lista, gerada automaticamente com a sequência de palavras fixadas no texto-fonte e no textoalvo

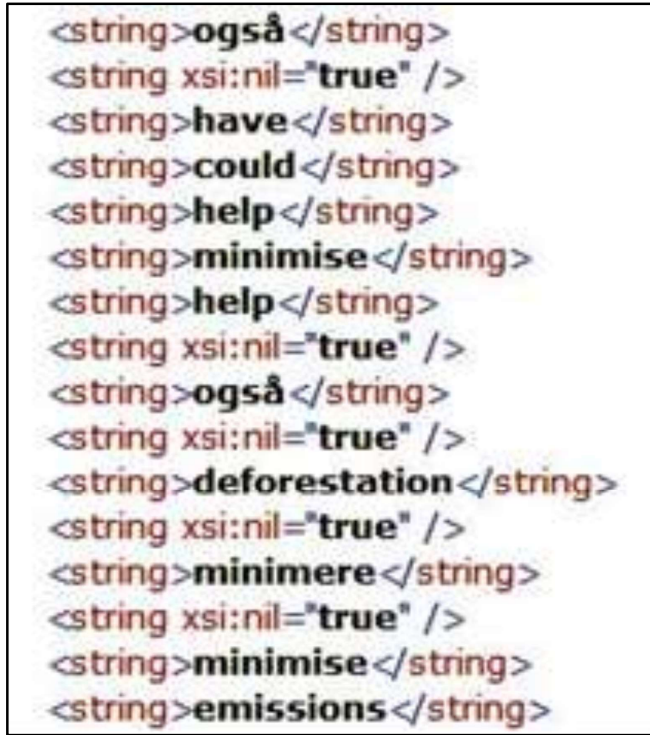

Nota: Observe-se que, em cinco casos, houve um registro de fixação, mas não foi possível associar as fixações a alguma palavra (xsi:nil="true").

As palavras às quais as fixações são automaticamente associadas pelo sistema estão listadas em outro lugar no arquivo XML. Em caso de sucesso, cada fixação do olhar será associada à palavra que estava em foco no momento em que o evento foi registrado. A Figura 3 mostra um trecho de tal lista.

\section{O desafio analítico: observações processuais preliminares}

Com os dados registrados organizados dessa forma estruturada, enfrentamos um novo desafio analítico. Todos os detalhes da atividade ocular e de digitação do tradutor podem ser examinados, mas, para que possam fazer sentido, precisam ser interpretáveis como constituintes de um modelo.

O tradutor cujos dados são apresentados nas Figuras 1 a 3 passou um tempo considerável olhando para o teclado durante a digitação. Por essa razão, há longos períodos de 
mais de $10 \mathrm{~s}$ sem dados oculares registrados no arquivo. Outra consequência disso são os períodos relativamente longos de digitação em que o tradutor não olha para o texto-fonte. Ademais, em razão da prolongada atenção visual dada ao teclado - que, em termos cognitivos, assemelha-se a um terceiro texto -, os dados do olhar na tela revelam que esse tradutor tinha que reler o texto-fonte regularmente para retomar o próximo segmento relevante desse texto.

$\mathrm{O}$ registro dos movimentos oculares permite visualizar a quantidade de trabalho envidado pelos olhos - e pelo cérebro humano - na leitura. Os desafios, do ponto de vista da pesquisa do processo tradutório, são investigar como a leitura, enquanto constituinte de um processo de tradução, difere de outros tipos de leitura e como essa leitura interage com outros processos cognitivos envolvidos na tradução.

Nossos resultados de 2007 - quando registramos os movimentos oculares de participantes de um experimento instruídos a ler, para compreensão, um texto escrito em língua estrangeira e, em seguida, os comparamos com os movimentos oculares registrados de participantes instruídos a digitar a sua tradução na L1 para um texto escrito em língua estrangeira que lhes fora apresentado na tela - revelaram que os movimentos oculares na leitura são altamente dependentes do propósito dessa leitura (cf. observações anteriores de YARBUS, 1967) e da natureza da tarefa de leitura. A tradução escrita envolve muito mais trabalho dos olhos e parece ser uma tarefa consideravelmente mais dispendiosa, em termos cognitivos, do que a simples leitura e compreensão ou até a leitura e tradução oral de um texto (JAKOBSEN; JENSEN, 2008, traduzidos neste volume). Isso pode se dar, em parte, porque o modo falado é mais automatizado do que o modo escrito, mas também, em certa medida, pode resultar do esforço óptico-motor necessário para ajudar o cérebro a acompanhar quais palavras do texto-fonte podem ser ou foram alinhadas a quais palavras do texto-alvo. $\mathrm{O}$ trabalho de alinhamento força o cérebro a instruir constantemente os olhos a alterarem entre o texto-fonte e o texto-alvo. Embora o rastreamento ocular forneça ampla evidência de que muitos tradutores têm uma memória espacial do texto muito precisa e podem alternar, com bastante precisão, entre sequências de caracteres em diferentes textos, tais transições podem também causar desorientação e demandar certo grau de reorientação e releitura. Tal "ruído" casual nos dados dificulta a deteç̧ão de regularidades.

Pode-se gerar um relatório preliminar das alternâncias de atenção entre o texto-fonte e o texto-alvo a partir de listas como aquelas mostradas nas Figuras 2 e 3, podendo-se também reconstruir os pontos nos quais houve digitação de texto. Tal relatório revela que os olhos 
estão constantemente envolvidos em três tipos básicos de atividade, a saber: (i) leitura do texto-fonte (TF); (ii) leitura do texto-alvo (TA); e (iii) monitoramento da atividade dos acionamentos de teclas e dos produtos da digitação. Sabemos que a tradução também deve estar ocorrendo, muito provavelmente em paralelo com outros processos, mas só existem evidências comportamentais indiretas dessa atividade.

No momento registrado nas Figuras 1 a 3, o tradutor tinha acabado de digitar "og de kunne også" (tradução para "and could also" [e também poderia]). O fragmento do TF processado no excerto da Figura 3 era "help minimise" [ajudar a minimizar]. Uma análise mais detalhada da sequência de fixações em palavras permite as seguintes observações e interpretações:

1. a palavra digitada mais recentemente ("også") foi fixada imediatamente após ser digitada (um exemplo do monitoramento da produção do TA);

2. a fixação de "have" [ter], que aparecia uma linha abaixo da palavra-alvo "help", ilustra o fenômeno de "undershooting", ou errar o alvo, conhecido dos estudos dos movimentos oculares quando de mudanças de linha durante a leitura. A distância de "også", no TA, até "help", no TF, requereu uma sacada quase do mesmo tamanho daquela necessária nas trocas de linha e, portanto, a palavra-alvo "help" aparentemente não foi fixada. É possível, contudo, que o cérebro do tradutor tenha percebido a palavra-alvo por meio da visão parafoveal, já que, após a rápida parada em "have”, a sacada deslocou-se para a palavra "could", à esquerda, que já havia sido traduzida;

3. como a palavra "could" já fora traduzida, uma possível razão para a releitura dessa palavra mais distante em detrimento da leitura da nova palavra-alvo do TF ("help"), mais próxima, pode ter sido a necessidade de estabelecer uma nova palavra-âncora mental para o próximo segmento do TF a ser processado;

4. com a âncora definida, o terreno mental tinha sido preparado para as duas próximas palavras-alvo, "help" e "minimise", a serem fixadas uma após a outra;

5. embora se esperasse que o tradutor fixasse também a palavra seguinte ("emissions", o objeto do verbo transitivo "minimise"), tal ação não ocorreu logo, talvez em uma indicação de que o tradutor não fizera uma análise sintática profunda do TF. Em vez disso, o olhar desse tradutor voltou ao TF

\footnotetext{
${ }^{9}$ A Figura 4 mostra o texto-fonte como apresentado na tela no experimento.
} 
para refixar brevemente a palavra "help" (e talvez "minimise") enquanto provavelmente formulava uma tradução;

6. antes de digitar a tradução, no entanto, o tradutor fixou a última palavra do atual TA, estabelecendo uma âncora-alvo à qual se prender para a tradução de "help minimise";

7. só então o tradutor digitou a tradução (não idiomática) "hjoelpe $i$ at minimere", sem olhar para a tela; e

8. por fim, foi monitorada a nova entrada de TF na tela (em uma fixação para a qual não foi identificada uma palavra correspondente).

Após executar essa sequência de ações, o tradutor estava pronto para proceder à tradução do próximo segmento, "emissions from deforestation" [emissões advindas do desflorestamento], quase da mesma maneira.

\section{Um padrão de processamento recorrente}

A observação dos movimentos oculares nos ajuda a entender a complexidade mecânica da tarefa de tradução escrita, mas os dados do olhar também nos auxiliam a chegar mais perto do cerne dos processos cognitivos envolvidos na tradução. A hipótese olho-mente (JUST; CARPENTER, 1980) aventa que o indivíduo olha para aquilo que de que se ocupa a sua mente. Demonstrou-se que essa correlação não se aplica universalmente durante o processo de leitura (cf. HYONA; LORCH JR.; RINCK, 2003), mas, embora essa correlação nem sempre seja exata, permanece o pressuposto básico de que os olhos (geralmente) fixam aquilo de que se ocupa a mente do indivíduo. Portanto, os dados dos movimentos oculares fornecem uma janela para a mente; e, ao visualizarmos o modo como ocorre a leitura e como ela interage com a digitação, obtemos a melhor imagem disponível de como os processos de tradução se coordenam na mente humana.

Por meio do registro estruturado da exata sucessão temporal das atividades executadas pelos olhos e pelas mãos dos tradutores podemos reformular antigas perguntas e começar a tentar respondê-las, como fizemos na seção anterior. Uma dessas perguntas refere-se à maneira como os tradutores segmentam a produção do TA. Em vez de nos limitarmos a uma descrição da segmentação com base nos aspectos temporais da produção textual (com sequências de alternância entre pausas e períodos de produção), podemos enriquecer nossa análise com dados oculares. Como acabamos de ver, os dados oculares fornecem fortes evidências a respeito de quanto do TF foi lido antes da produção de determinado trecho do 
TA. Isso nos dá uma ideia exata de qual segmento do TF foi lido imediatamente antes da digitação do trecho correspondente no TA. Em vez de definirmos mecanicamente um segmento ou uma unidade de tradução pela ocorrência de uma pausa de certa duração no processo de digitação, agora podemos identificar - de forma mais qualitativa e com maiores detalhes - o segmento do TF que estava sendo lido e o segmento correspondente do TA que estava sendo digitado, independentemente da duração das pausas entre os segmentos.

Outra pergunta importante está relacionada com a coadunação dos processos de compreensão, tradução e formulação. A inclusão de dados do olhar proporciona uma imagem mais detalhada da complexidade comportamental e cognitiva envolvida na interação olhomão (e cérebro) que ocorre durante o processo tradutório. Embora ainda tenhamos somente evidências indiretas do processamento da tradução, contamos com evidências mais fortes das etapas percorridas pelo cérebro do tradutor humano que nos permitem computar a trajetória dos olhos e os movimentos dos dedos no teclado durante a execução de uma tradução.

As observações e interpretações realizadas na seção anterior podem ser resumidas esquematicamente. Na Tabela 1, as ações foram tabuladas para dar uma visão da sequência de ações e de resultados.

Tabela 1 - Alternâncias de atenção visual entre texto-fonte (TF) e texto-alvo (TA) com base na associação automática dos dados do olhar às respectivas palavras visualizadas

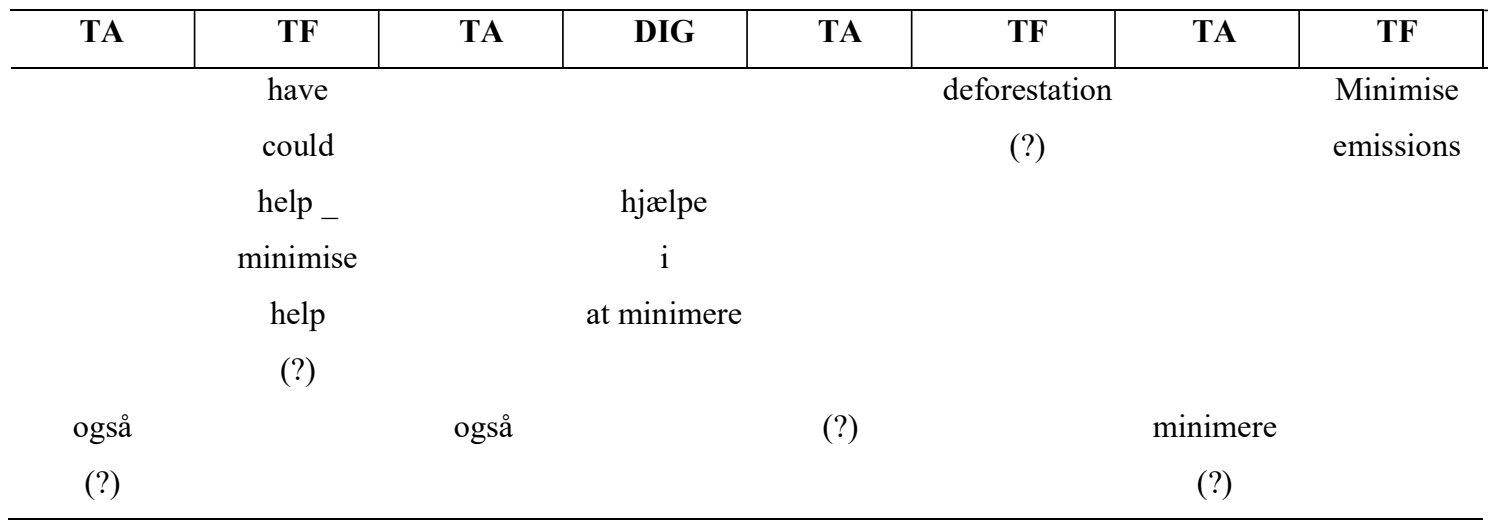

Nota: A coluna DIG indica onde a digitação ocorreu. Após a segunda fixação de "ogsă", foram digitadas as palavras "hjcelpe $i$ at minimere". Os sinais de interrogação indicam fixações para as quais não foi possível realizar um mapeamento.

A sequência de ações executadas pelo tradutor humano em tela pode agora ser hipoteticamente abstraída em um pequeno algoritmo. Começando por um ato de compreensão, o ciclo de processos cognitivos e motores que podemos estabelecer com base nos dados do exemplo acima envolve as seis seguintes etapas: 
1. movimento ocular para leitura do próximo segmento do TF (e elaboração de uma tradução para o segmento);

2. redirecionamento do olhar para o TA com vistas à localização da área de digitação e leitura da atual palavra-âncora do TA;

3. digitação da tradução do segmento do TF;

4. monitoramento do processo de digitação e do texto resultante na tela;

5. redirecionamento do olhar para o TF com vistas à localização da área de leitura relevante; e

6. leitura da atual palavra-âncora do TF.

Essas etapas devem ser vistas como parte de um microciclo completo em que algumas dessas etapas (ou partes delas) podem ser ignoradas ou, ao contrário, repetidas diversas vezes. Por exemplo, na etapa 2, o olhar moverá em direção ao TA, mas não necessariamente a uma palavra-âncora. Também percebemos que, com frequência, o olhar pode alternar várias vezes entre a(s) palavra(s) do TF que estão sendo processadas (etapa 2) e a tradução que está sendo digitada (etapas 3 e 4). Um modelo mais detalhado deverá, portanto, acrescentar subcategorias a cada etapa ou a algumas delas e indicar que, por exemplo, as etapas 3 e 4 podem ser executadas de maneiras bastante diferentes, dependendo das habilidades de digitação do tradutor. Também é importante notar que as etapas 3 e 4 são, em certa medida, simultâneas. $O$ monitoramento acontece concomitantemente à digitação do texto, embora o monitoramento (da tela) frequentemente continue após a digitação do texto ter terminado. Contudo, mesmo sem tais detalhes, o modelo permite prever com um alto grau de probabilidade que a etapa 1 será seguida pela etapa 2, a qual, por sua vez, será seguida pela etapa 3, e assim por diante.

Como se pode observar, é considerável o esforço óptico-ocular envolvido ao se ajudar o cérebro a acompanhar quais palavras do TF já foram lidas e traduzidas, quais palavras podem ser ou já foram alinhadas com quais palavras do TA e quais palavras do TA já foram digitadas (e como tudo isso foi feito). O trabalho de alinhamento ("vertical") entre as duas línguas envolvidas força o cérebro a constantemente instruir os olhos a alternarem entre o TF e o TA. A ligação sintagmática monolíngue ("horizontal”) também exige releitura quando novas porções de texto são adicionadas ao texto já existente, seja visual ou tipograficamente.

\section{Análise dos dados da amostra}

A disponibilidade de grandes volumes de dados estruturados nos levar a buscar, a partir de aplicações de métodos estatísticos a grandes corpora de dados, por evidências para 
as observações que fazemos com base em pequenas amostras de dados. Para isso, precisamos ter certeza de que os dados coletados satisfaçam critérios empíricos básicos - por exemplo, em relação à integralidade. Como fica evidente na amostra apresentada (cf. principalmente na Figura 3), o sistema atual nem sempre tem sucesso na associação das fixações às respectivas palavras lidas.

Um desafio mais básico diz respeito à identificação das fixações. Trata-se de um desafio ao mesmo tempo técnico e teórico. O rastreador ocular usado em nossos experimentos é uma máquina de $50 \mathrm{~Hz}$ (i.e., registra amostras do olhar em intervalos de $20 \mathrm{~ms}$ ). No método tradicional, com esse equipamento, uma fixação ocorre quando cinco amostras consecutivas são registradas dentro de uma área específica (e.g., não mais que 40 pixels de distância). Isso significa que uma fixação sempre é registrada como tendo uma duração de, pelo menos, 100 ms. Embora definições mais sofisticadas, baseadas na velocidade, venham ganhando maior aceitação, isso não muda o fato de que o que constitui uma fixação é altamente dependente do equipamento utilizado. Seria absurdo, por exemplo, usar a definição tradicional em dados obtidos por meio de um rastreador ocular de $1000 \mathrm{~Hz}$ e dizer que existe uma fixação de apenas $5 \mathrm{~ms}$, mas, ao mesmo tempo, pode ser totalmente aceitável dizer que as fixações podem ocasionalmente ter durações inferiores a 100 ms. Há também um possível limite máximo que deve ser considerado; é preciso ter em conta a duração máxima de uma fixação antes de termos que a dividir em várias outras.

Existem diversos outros desafios técnicos para a obtenção de bons dados de leitura a partir de experimentos de tradução, especialmente por causa das frequentes mudanças de atenção visual e da natureza descontínua da leitura. Ademais, o registro de dados do olhar é sensível a um grande número de variáveis, incluindo movimentos da cabeça, acurácia da calibração, piscadas e forma dos cílios do tradutor. Com dados de má qualidade, há o perigo de que as fixações, embora bem definidas, não sejam sequer identificadas. Obviamente, se as fixações não forem identificadas, não há nada a ser mapeado.

Para ilustrar a variabilidade que enfrentamos nos diferentes registros de dados, a Figura 4 apresenta uma sucessão de fixações (ainda no mesmo trecho) fornecida por outro software. Esta figura apresenta uma plotagem do olhar (gaze plot) gerada pelo software ClearView, da empresa Tobii, que registra a sequência de fixações e sacadas e as plota na tela em uma posição calculada e aproximada, sem qualquer ajuste ao que é mostrado na tela. Quando a plotagem do olhar é colocada sobre o texto que estava sendo apresentado no momento do registro, pode-se notar que, de acordo com o ClearView, a quantidade de 
fixações provavelmente superou as 11 que haviam sido associadas com sucesso a alguma palavra pelo módulo GWM integrado ao Translog (cf. Figura 3).

Figura 4 - Trecho de uma plotagem do olhar (gaze plot) gerada pelo software ClearView (635-664)

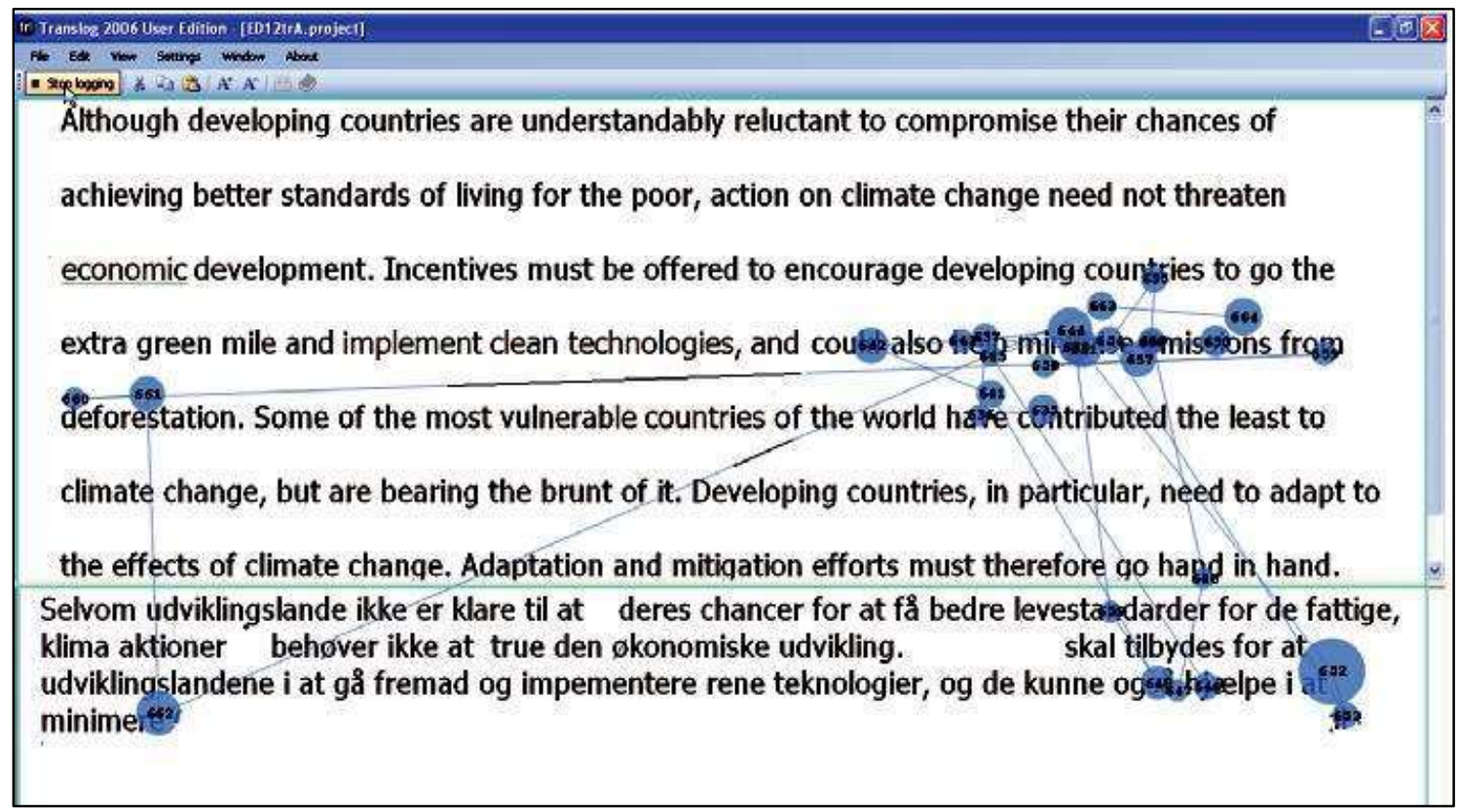

Nota: As fixações 640-664 foram registradas com o mesmo intervalo de tempo e no mesmo evento que aquelas registradas nas Figuras 2 a 3. As fixações 635-639 foram anteriores.

A representação das fixações na Figura 4 ilustra alguns dos problemas técnicos e teóricos envolvidos em se conectar, com confiabilidade, as fixações registradas àquilo que achamos que provavelmente estava sendo visto e lido. Esses problemas conduzem ao cerne da relação olho-mente: como as fixações calculadas por nosso equipamento se correlacionam com a experiência mental da leitura de uma sequência de palavras? O nosso equipamento registra o que o olho físico parece estar focando, mas a correspondência exata desse registro com o que a mente vê é um problema de grande magnitude. Muitas das fixações não são registradas como tendo acontecido sobre uma palavra específica, mas aparecem um pouco abaixo ou acima de uma palavra, ou mesmo entre palavras ou em um extremo de uma palavra; ou então duas (ou mais) fixações sucessivas são registradas na mesma palavra. O mapeamento manual de tais dados é um lembrete muito esclarecedor de que o que chamamos de fixação não é um conceito muito bem definido nem um objeto facilmente identificável, mas uma abstração tecnológica e teórica com certa sustentação no comportamento.

Uma maneira de entender os dados do olhar representados na Figura 4 é interpretá-los à luz de um modelo de leitura ou, melhor ainda, à luz de um modelo processual de tradução, o 
qual inclui um modelo do comportamento de leitura provável. A função de tal modelo é reduzir, o máximo possível, a distância entre as fixações registradas e as palavras que realmente estavam sendo lidas pelo participante. A Tabela 2 apresenta o resultado desse processo.

Tabela 2 - Fixações mapeadas automaticamente pelo Translog/GWM comparadas àquelas mapeadas manualmente a partir do ClearView.

\begin{tabular}{|c|c|c|c|c|c|}
\hline \multirow{3}{*}{$\begin{array}{l}\text { Palavras fixadas } \\
\text { Translog }\end{array}$} & \multicolumn{5}{|c|}{ Período de tempo: $13 \mathrm{~s}, 509-521 \mathrm{~s}$ na tarefa } \\
\hline & \multicolumn{5}{|c|}{ Registro de fixações no ClearView, associado manualmente às respectivas palavras } \\
\hline & Fixação & Palavra do TF & Palavra do TA & Dur & Comentário \\
\hline & 635 & Contributed & & 239 & \\
\hline & 636 & have & & 120 & linha abaixo de "help" \\
\hline & 637 & help & & 179 & \\
\hline & 638 & minimise & & 239 & \\
\hline & 639 & & levestandarder & 100 & descendo o olhar para o "fim" do TA \\
\hline også (+não mapeada) & 640 & & også & 259 & \\
\hline have & 641 & have & & 199 & linha abaixo de "help" \\
\hline could & 642 & could & & 299 & \\
\hline help & 643 & help & & 140 & \\
\hline minimise & 644 & minimise & & 399 & \\
\hline help & 645 & help & & 120 & \\
\hline (unmapped) & 646 & & også & 159 & \\
\hline også & 647 & & også & 120 & \\
\hline & 648 & hand & & 120 & subindo o olhar para "emissions" \\
\hline & 649 & emissions & & 179 & primeira metade da palavra fixada \\
\hline & 650 & emissions & & 219 & segunda metade da palavra fixada \\
\hline & 651 & minimise & & 319 & \\
\hline & 652 & & at & 698 & \\
\hline & 653 & & at & 179 & \\
\hline & 654 & minimise & & 179 & \\
\hline & 655 & countries & & 160 & linha acima de "emissions" \\
\hline & 656 & emissions & & 140 & primeira metade da palavra fixada \\
\hline & 657 & emissions & & 279 & primeira metade da palavra fixada \\
\hline & 658 & minimise & & 139 & \\
\hline & 659 & from & & 140 & \\
\hline deforestation & 660 & defo(restation) & & 120 & \\
\hline & 661 & (defo)restation & & 279 & \\
\hline minimere & 662 & minimere & & 419 & \\
\hline minimise & 663 & minimise & & 199 & \\
\hline emissions & 664 & emissions & & 321 & \\
\hline
\end{tabular}

Nota: Entre as fixações 647 e 648, houve um intervalo de 2,013 s em que a palavra "hjcelpe" foi digitada. Entre as fixações 651 e 654, houve um intervalo de 3,054 s em que foram digitadas as palavras " $i$ at minimere". 
As fixações 640 a 647 puderam ser mapeadas identicamente sem nenhum problema. A fixação 640 foi interpretada pelo Translog/GWM como correspondente a duas fixações separadas, mas não foi possível mapear a segunda. A fixação 646 parece, pelo ClearView, estar direcionada à palavra "hjoelpe", mas, uma vez que as informações de data e hora mostram que essa palavra ainda não havia sido digitada no momento da fixação, ela teve de ser associada à palavra "også".

As fixações 660 a 664 também foram mapeadas quase identicamente. O Translog/GWM aglutinou a 660 e a 661 em uma fixação única na palavra "deforestation". A fixação 663 foi registrada no ClearView como acontecendo entre "minimise" (linha 4) e "countries" (linha 3). Com base na proximidade, alinharíamos essa fixação com "countries", mas essa associação entra em conflito com o modelo de 6 etapas descrito anteriormente, que prevê que a fixação que acontece depois de uma fixação de monitoramento do texto digitado (etapa 4) será seguida por um redirecionamento do olhar para o TF (etapa 5), seguida por uma fixação em uma palavra-âncora (etapa 6). A trajetória esperada seria, portanto: "minimere" (monitoramento da digitação) $\rightarrow$ palavra-âncora "minimise", com, talvez, uma rápida parada próximo à palavra-alvo seguinte ("emissions") para ajustar a trajetória. Portanto, a decisão foi de associar essa fixação à palavra "minimise", em concordância com o modelo, e, de modo semelhante, associar a fixação 664 à palavra "emissions", em vez da expressão "to go", na linha acima.

Em suma, em relação às fixações 640 a 647 e 660 a 664, há uma concordância quase perfeita entre o mapeamento automático do Translog/GWM e o mapeamento manual da representação do olhar a partir dos dados registrados com o ClearView. Contudo, os dados nem sempre dão suporte a interpretações idênticas. As fixações 648 a 659 do ClearView, por exemplo, não foram mapeadas pelo Translog/GWM; não foram sequer identificadas como fixações. Isso pode ter decorrido do fato de que, entre as fixações 647 e 648, houve um intervalo de 2,013 s em que o tradutor digitou a palavra "hjoelpe" provavelmente olhando para o teclado. Quando o olhar do tradutor voltou à tela, o GWM não o reconheceu tão rapidamente quanto o ClearView. Seja qual for a razão técnica para tal (quiçá uma ligeira inconsistência entre os dados de calibração do ClearView e o do GWM para esse tradutor), a falta de dados é um problema sério, embora, nesse caso específico, seja possível preencher a lacuna por meio do mapeamento manual das fixações registradas no ClearView, como foi feito na Tabela 2. 
Como veremos, os dados ilustram que as seis etapas de nosso modelo não são sempre seguidas sequencialmente à risca. As etapas podem ser ignoradas ou repetidas várias vezes, e o processamento pode, ocasionalmente, voltar a etapas anteriores nos casos em que o processamento sequencial não é capaz de fornecer um resultado relevante. Na essência, no entanto, encontramos o mesmo ciclo básico de processamento quando reconstruímos os dados ausentes no GWM. Essa é uma ótima notícia para nossas possibilidades de analisar os dados automaticamente e para construirmos um modelo computacional para o processo de tradução humana. Observemos mais de perto a sequência de fixações 643 a 660 que foram mapeadas manualmente.

Se simplificarmos um pouco a sequência (agrupando todas as múltiplas fixações sucessivas em uma mesma palavra e descartando a fixação irregular em "countries"), obtemos a seguinte série de fixações: "hand", "emissions", "minimise", "at", "minimise", "emissions", "minimise", "from", "deforestation". Acompanhando nosso modelo, a sequência seria interpretada como representando as etapas descritas a seguir.

Após fixar uma sequência de novas palavras do TF, ou seja, "help", "minimise" e "help" (etapa 1, fixações 643 a 645), o foi redirecionado para o TA, onde as fixações 646 e 647 identificaram a palavra-âncora "også", em duas fixações repetidas (etapa 2). A isso se seguiu a digitação de "hjoelpe" (etapa 3), tradução da primeira das duas novas palavras lidas em 643 a 645. A ausência de dados de fixação durante os $2 \mathrm{~s}$ subsequentes indica que a atenção visual (monitoramento) esteve apenas no teclado (etapa 4). Em seguida, o olhar foi redirecionado ao próximo trecho do TF (etapa 5). Uma vez que o segmento novo subsequente ("minimise emissions") se sobrepôs ao anterior ("help minimise"), "minimise" funcionou como a âncora mental (etapa 6) para o novo segmento subsequente ("minimise emissions", etapa 1). Essa etapa foi seguida por um redirecionamento do olhar para o TA (etapa 2) e, em seguida, para o teclado, enquanto a tradução do restante de "minimise emissions" era digitada ("i at minimere", etapa 3). O fato de que não houve fixação em âncora alguma do TA e o fato de que dois segmentos sucessivos do TF se sobrepuseram sugerem que a expressão "help minimise" foi tratada como um único segmento tradutório, mesmo que "emissions" só tenha sido fixada depois que tradução de "help" havia sido digitada. Durante a digitação de " $i$ at minimere" (etapa 3), que durou 3,054 s, foram registradas duas fixações em "at", indicando que a atenção visual foi alternada do teclado para a tela (durante a etapa 4) por cerca de um terço $(0,9 \mathrm{~s})$ do tempo utilizado para digitar esse trecho da tradução. Após o período de digitação de $3 \mathrm{~s}$, que pode indicar uma incerteza cognitiva sobre a solução idiomática 
produzida nesse ponto, iniciou-se um novo ciclo, começando com o redirecionamento do olhar para o TF (etapa 5), seguido pela fixação da palavra-âncora do TF “minimise” (etapa 6, fixação 654). A isso se seguiu a leitura de novo trecho do TF ("emissions from deforestation"), que, ao que parece, foi um segmento muito longo para ser processado por esse tradutor em um único ciclo. Logo após, a palavra-âncora "minimise" e seu complemento "emissions" foram fixadas novamente, quando então o tradutor pôde redirecionar o olhar para o TA (etapa 2) e digitar a tradução de "emissions" (etapa 3).

Como se pode observar, o modelo básico de processamento é reconhecível até em uma sequência caracterizada por fixações repetidas e recuos. O modelo tem, portanto, potencial para ser utilizado na resolução de problemas de mapeamento de fixações e para diagnosticar problemas de análise sintática ou de construção de significados. O modelo também cria uma nova oportunidade para se registrar computacionalmente a sequência de novos segmentos do TF lidos pelo tradutor e para alinhar automaticamente os segmentos lidos do TF e suas respectivas traduções.

\section{Conclusão e perspectivas: estamos chegando a um modelo computacional da tradução humana?}

$\mathrm{O}$ uso conjunto do rastreamento ocular e do registro de acionamentos de teclas e mouse tornou possível estudar - com um nível de detalhe jamais alcançado - quais unidades de texto-fonte ou de texto-alvo estão sendo processadas pelo tradutor em determinado momento. Os dados obtidos por meio desse registro integrado fornecem evidências tangíveis da complexa atividade de processamento realizada pelo tradutor. Desde o princípio, o objetivo do desenvolvimento do Translog apresentado no presente artigo foi compreender, a partir de evidências comportamentais, qual é a natureza dessa atividade de processamento, quais são as etapas nela envolvidas, quais são os segmentos lidos e alinhados e como é feito o monitoramento de todo esse processo. Nossa análise detalhada de uma pequena amostra de dados do olhar e de acionamentos de teclas mostrou que, no atual estado da arte, ainda existem alguns problemas técnicos a serem resolvidos. Contudo, a análise também indica que parece haver um microciclo de etapas de processamento no cerne de uma tarefa tradutória. A sequência integrada de dados do olhar e de acionamentos de teclas sugere que a dinâmica básica do processamento tradutório pode ser descrita em termos de seis etapas básicas.

No atual estado de desenvolvimento tecnológico, parece relevante, talvez mesmo necessário, analisar pequenos volumes de dados de movimentos oculares e de acionamentos 
de teclas e mouse de forma manual e seletiva, tanto para mensurar a taxa de sucesso do mapeamento automático do sistema quanto para, a partir de amostras pequenas de dados limpos e cuidadosamente controlados, aventar hipóteses que possam ser testadas em amostras maiores de dados que contenham maior quantidade de ruídos. Não obstante, isso não deve nos impedir de buscar um objetivo mais amplo. O potencial para análise computacional em larga escala dos dados das atividades do tradutor já existe, ou existirá em breve; e a perspectiva de criação de um modelo computacional de como os tradutores humanos expertos executam uma tarefa parece ser alcançável.

O eventual sucesso de um modelo computacional da tradução humana depende fundamentalmente da qualidade dos dados brutos registrados e da robustez da interpretação automática dos dados realizada por nosso sistema, principalmente na forma como as fixações são identificadas e no algoritmo de mapeamento. Essas interpretações serão fundamentadas, inicialmente, pelo conhecimento sobre tradução humana que vem sendo acumulado na comunidade de pesquisa. No entanto, esse conhecimento pode ser enriquecido pela descoberta de novos padrões e regularidades em grandes volumes de dados sobre o comportamento das mãos e dos olhos dos tradutores humanos.

\section{Referências}

ENGLUND DIMITROVA, B. Expertise and explicitation in the translation process. Amsterdã/Filadélfia: John Benjamins, 2005.

ENGLUND DIMITROVA, B.; TISELIUS, E. Exploring retrospection as a research method for studying the translation process and the interpreting process. In: MEES, I.; ALVES, F.; GÖPFERICH, F. (Ed.). Methodology, technology and innovation in translation process research. Copenhagen: Samfundslitteratur, 2009. p. 109-134.

ERICSSON, K. A.; SIMON, H. A. Protocol analysis: verbal reports as data. Cambridge, Mass.: MIT, 1984.

HANSEN, G. Störquellen in Übersetzungsprozessen: eine empirische Untersuchung von Zusammenhängen zwischen Profilen, Prozessen und Produkten. Frederiksberg: Samfundslitteratur, 2005.

HANSEN, G. Erfolgreich Übersetzen. Entdecken und Beheben von Störquellen. Tübingen: Narr.

HYÖNÄ, J., LORCH JR., R. F. AND RINCK, M. 2003. Eye movement measures to study global text processing. In: HYÖNÄ, J.; RADACH, R.; DEUBEL, H. (Ed.). The mind's eye: cognitive and applied aspects of eye movement research. Amsterdã: Elsevier, 2006. p. 313 334. 
HYRSKYKARI, A. Eyes in attentive interfaces: experiences from creating iDict, a gazeaware reading aid. Doctoral dissertation. Finland: University of Tampere, 2006.

HYRSKYKARI, A., MAJARANTA, P., AALTONEN, A.; RÄIHÄ, K.-J. 2000. Design issues of iDICT: a gaze-assisted translation aid. In: EYE TRACKING RESEARCH \& APPLICATION, Palm Beach Gardens, 06-08 nov. 2000. Proceedings.... Nova York: ACM, 2000. p. 9-14.

JAKOBSEN, A. L. Effects of think aloud on translation speed, revision and segmentation. In: ALVES, F. (Ed.). Triangulating translation: perspectives in process oriented research. Amsterdã/Filadélfia: John Benjamins, 2003. p. 69-95.

JAKOBSEN, A. L. Investigating expert translators' processing knowledge. In: DAM, H. V.; ENGBERG, J.; GERZYMISCH-ARBOGAST, H. (Ed.). Knowledge systems and translation. Berlim/Nova York: De Gruyter, 2005. p. 173-189.

JAKOBSEN, A. L.; JENSEN, K. T. H. Eye movement behaviour across four different types of reading task. In: GÖPFERICH, S.; JAKOBSEN, A. L.; MEES, I. M. (Ed.). Looking at eyes: eye-tracking studies of reading and translation processing. Copenhagen:

Samfundslitteratur, 2008. p. 103-124.

JAKOBSEN, A. L.; SCHOU, L. Translog documentation. In: HANSEN, G. (Ed.) Probing the process in translation: methods and results. Copenhagen: Samfundslitteratur, 1999. p. 151186.

JUST, M. A.; CARPENTER, P. A. A theory of reading: from eye fixations to comprehension. Psychological Review, v. 87, p. 329-354, 1980.

RADACH, R.; KENNEDY, A.; RAYNER, K. Eye movements and information processing during reading. Hove: Psychology Press, 2004.

RAYNER, K. Eye movements in reading and information processing: 20 years of research. Psychological Bulletin, v. 124, n. 3, p. 372-422, 1998.

RAYNER, K.; POLLATSEK, A. The psychology of reading. Englewood Cliffs: Prentice Hall, 1989.

YARBUS, A. L. Eye movements and vision. Traduzido por Basil Haigh. Nova York: Plenum Press, 1967. 